\title{
Combination of Trabectedin With Oxaliplatinum and 5-Fluorouracil Arrests a Primary Colorectal Cancer in a Patient-derived Orthotopic Xenograft Mouse Model
}

\author{
GUANGWEI ZHU ${ }^{1,2,3,4}$, MING ZHAO ${ }^{1}$, QINGHONG HAN ${ }^{1}$, YUYING TAN ${ }^{1}$, YU SUN ${ }^{1,2}$, \\ MICHAEL BOUVET ${ }^{2}$, SHREE RAM SINGH ${ }^{5}$, JIANXIN YE ${ }^{3,4}$ and ROBERT M. HOFFMAN ${ }^{1,2}$ \\ ${ }^{1}$ AntiCancer, Inc., San Diego, CA, U.S.A.; \\ ${ }^{2}$ Department of Surgery, University of California, San Diego, CA, U.S.A.; \\ ${ }^{3}$ Department of Gastrointestinal Surgery 2 Section, \\ The First Hospital Affiliated to Fujian Medical University, Fuzhou, P.R. China; \\ ${ }^{4}$ Key Laboratory of Ministry of Education for Gastrointestinal Cancer, \\ Fujian Medical University, Fuzhou, P.R. China; \\ ${ }^{5}$ Basic Research Laboratory, National Cancer Institute, Frederick, MD, U.S.A.
}

\begin{abstract}
Background/Aim: In the present study, we aimed to determine the efficacy of trabectedin (TRAB) combined with oxaliplatinum (OXA)+5-fluorouracil (5-FU) on a colorectal cancer (CRC) patient-derived orthotopic xenograft (PDOX) mouse model. Materials and Methods: A patient CRC tumor previously established in nude mice was implanted subcutaneously in transgenic green fluorescence protein (GFP)-expressing nude mice. Harvested tumor fragments were transplanted orthotopically in nontransgenic nude mice. Mice were randomized into three groups: Group 1 (G1), untreated-control; Group $2(G 2)$, OXA+5-FU; Group 3 (G3), TRAB+OXA+5-FU. Tumor width, length, and mouse body weight were measured twice a week. Results: Both treatment groups inhibited tumor growth compared to the untreated control group. The combination of TRAB, OXA and 5-FU was significantly more efficacious than $O X A+5-F U$ and arrested tumor growth. No significant changes were observed in body-
\end{abstract}

Correspondence to: Robert M. Hoffman, AntiCancer, Inc, 7917 Ostrow St, San Diego, CA, 92111, U.S.A. Tel: +1 8586542555, email: all@anticancer.com; Jian-Xin Ye, Department of Gastrointestinal Surgery 2 Section, The First Hospital Affiliated to Fujian Medical University, 20th, Chazhong Road, Fuzhou, Fujian 350005, P.R. China Tel: +86 13809553280, e-mail: yejianxinfuyi@126.com; Shree Ram Singh, Basic Research Laboratory, National Cancer Institute, Frederick, MD, 21702, U.S.A. Tel: +1 3018467331, e-mail: singhshr@mail.nih.gov

Key Words: Colorectal cancer, trabectedin, oxaliplatinum, 5fluorouracil, combination therapy, PDOX. weight in any of the three groups. Conclusion: TRAB, OXA and 5-FU combination has clinical potential for this and other CRC patients.

Currently-available treatment strategies for colorectal cancer (CRC) mainly include surgical resection, radiotherapy and adjuvant chemotherapy. Oxaliplatinum (OXA)-based chemotherapy after surgical resection is one of the most frequently used therapeutic strategies (1). OXA combined with 5-fluorouracil (5-FU) has increased the survival rate in patients with CRC (2). However, a large proportion of patients with CRC receiving chemotherapy recur and develop chemo-resistant metastasis (3). Therefore, more effective therapies are needed for metastatic CRC.

To accomplish this goal, we have developed a patientderived orthotopic xenograft (PDOX) nude mouse model for many tumor types (4-13). To test the response of various chemotherapies on individual CRC patients, we have also developed CRC PDOX nude-mouse models and orthotopic cell line (13-21).

Trabectedin (TRAB) has been used for treating many cancer types $(22,23)$. TRAB is effective against many tumors resistant to alkylating agents (24). However, there are few studies where it has been shown that TRAB is active in CRC. Stevens et al., (25) have reported that several colorectal cell lines are highly resistant to cisplatinum and sensitive to TRAB. Izbicka et al. (23) and Twelves et al. (26) have shown that CRC patients could benefit from TRAB. In the present study, we show that TRAB is efficacious on a CRC PDOX mouse model in combination with OXA+5-FU. 


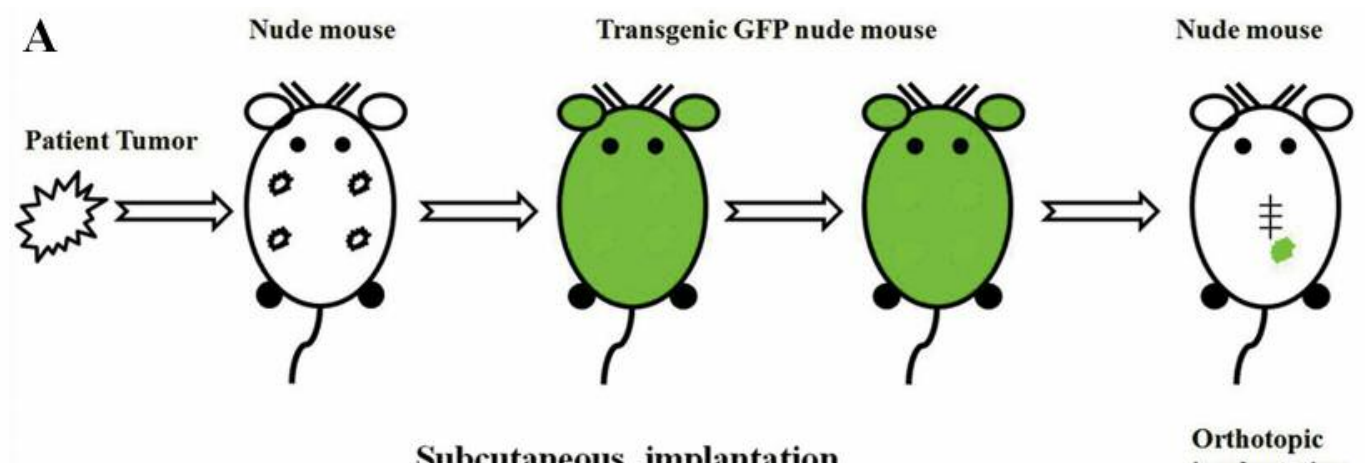

Subcutaneous implantation implantation

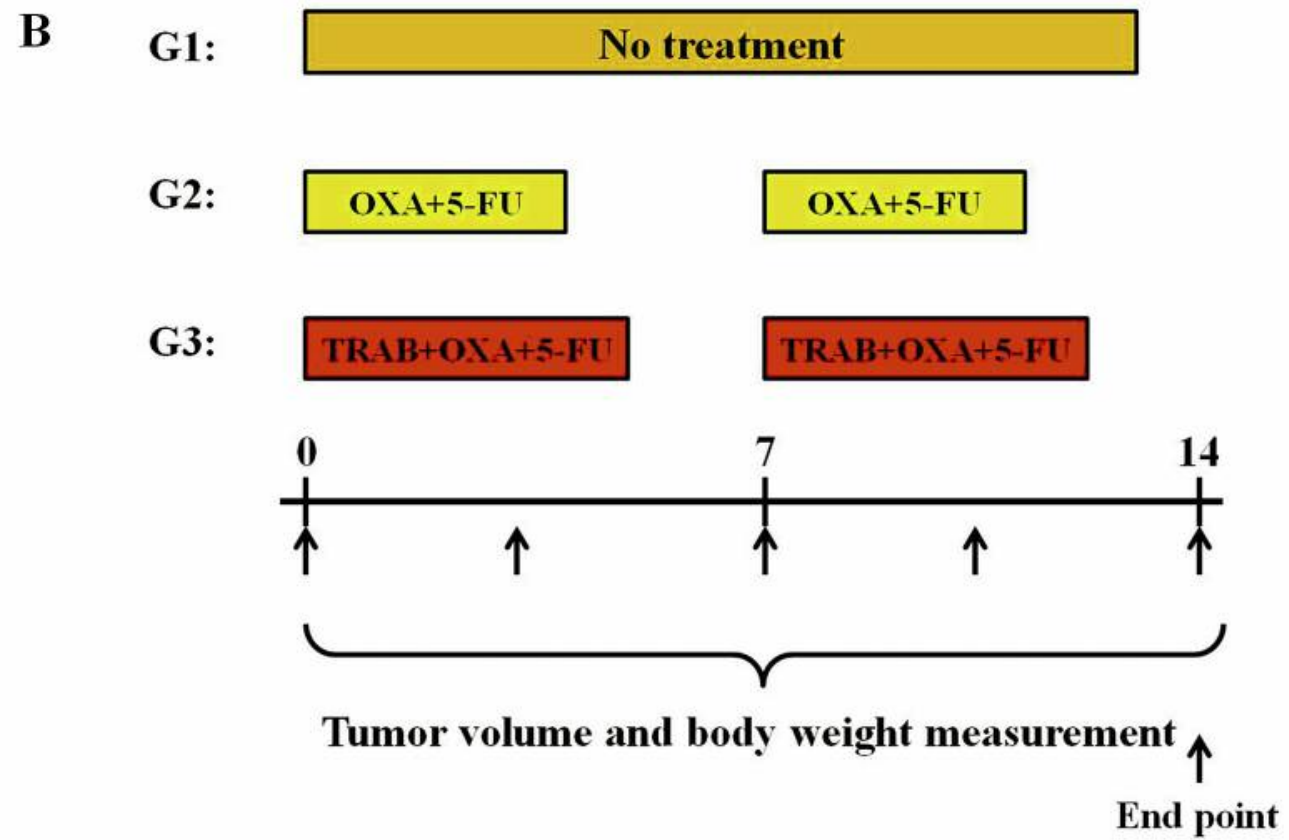

Figure 1. Establishment of a patient-derived orthotopic xenograft (PDOX) model and drug treatment schema. (A) Schematic illustration of the surgical orthotopic implantation (SOI) for establishment of imageable PDOX (iPDOX) models of human colorectal cancer. (B) Treatment regime and quantitative drug efficacy. Treatment protocol. G1: untreated control (n=7); G2: treated with OXA+5-FU (OXA $6 \mathrm{mg} / \mathrm{kg}+5-\mathrm{FU} 50 \mathrm{mg} / \mathrm{kg} ; \mathrm{i} . \mathrm{p}$., weekly for 2 weeks); G3: treated with TRAB+OXA+5-FU (TRAB $0.15 \mathrm{mg} / \mathrm{kg}$, i.v. and OXA $6 \mathrm{mg} / \mathrm{kg}+5-F U 50 \mathrm{mg} / \mathrm{kg}$; i.p., weekly for 2 weeks). All treated mice were sacrificed on the endpoint day, and tumors were resected for further histological evaluation.

\section{Materials and Methods}

Mice. Athymic nu/nu nude mice 4- to 6-weeks and transgenic green fluorescence protein (GFP) expressing athymic nu/nu mice were obtained from AntiCancer Inc. (San Diego, CA, USA). All surgical procedures and imaging were performed in accordance with an AntiCancer Inc. Institutional Animal Care and Use Committee (IACUC)-protocol specifically approved for this study, and in accordance with the principles and procedures outlined in the National Institutes of Health Guidelines for the Care and Use of Animals under Assurance Number A3873-1 (11). Mouse housing, feeding, anesthesia and surgical procedures were performed as described in previous publications $(11,27)$. The mice were humanely sacrificed based our previous publication (27).
Patient-derived tumor. The primary tumor was previously obtained from a patient with CRC in the Division of Surgical Oncology, University of California, San Diego (UCSD). The patient did not receive any chemotherapy or radiotherapy prior to surgery. Fresh tumor tissues were obtained from the patient at surgery with informed patient consent and Institutional Review Board (IRB) approval. The CRC PDOX mouse model (iPDOX) was established using the surgical orthotopic implantation (SOI) technique, as previously reported (14).

Establishing the imageable CRC PDOX model. CRC samples were cut into $5 \mathrm{~mm}^{3}$ fragments and implanted subcutaneously in nude mice. The resulting $\mathrm{CRC}$ tumors grown in non-transgenic nude mice were harvested, cut into $5 \mathrm{~mm}^{3}$ fragments, and implanted 
A

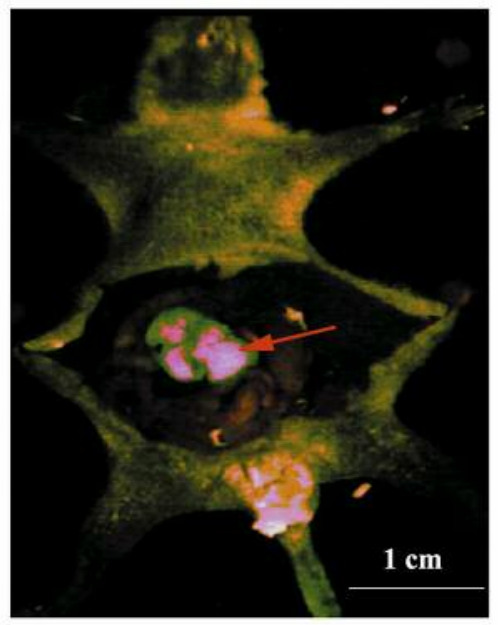

G1: No treatment
B

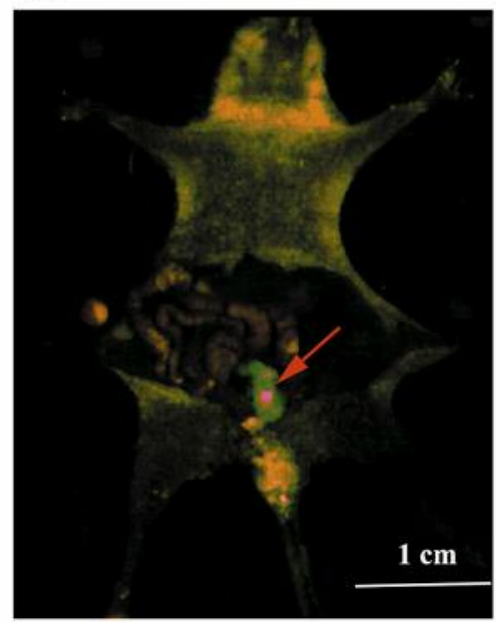

G2: OXA+5-FU
C

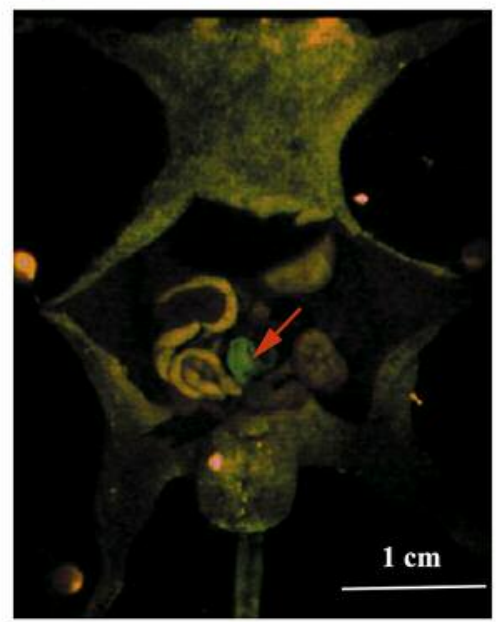

G3:TRAB+OXA+5-FU

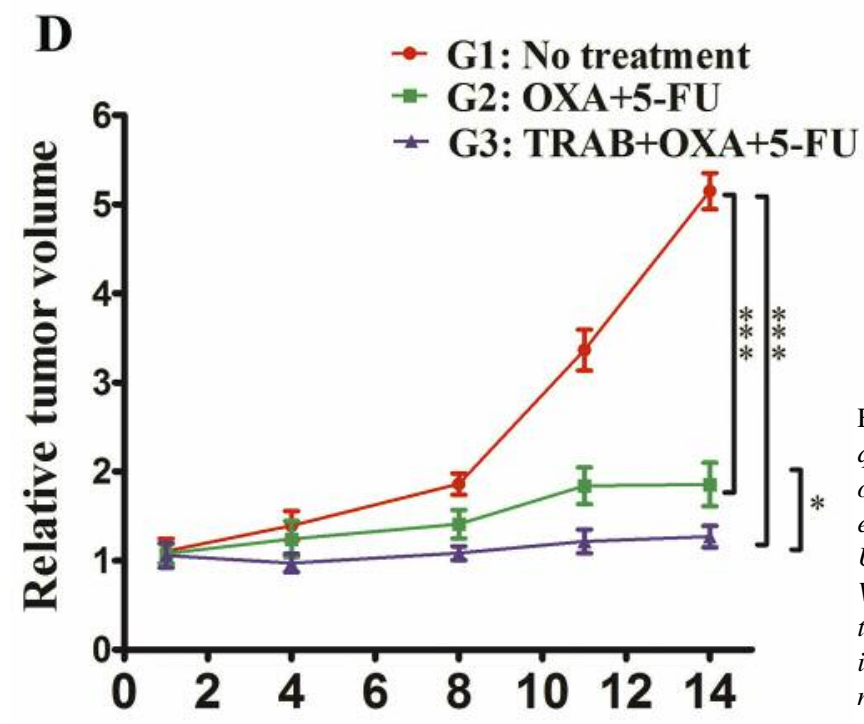

Figure 2. Imaging of PDOX tumors treated with each drug, and quantitative efficacy of chemotherapy on the CRC PDOX model. Images of representative PDOX mouse models from each treatment group at the endpoint. Arrows indicate GFP-expression of tumor stromal cells. (A) Untreated control. (B) OXA+5-FU. (C) TRAB+OXA+5-FU. The Fluor Vivo Imaging System was used (28). (D) Line graphs indicate relative tumor volume (ratio of tumor volume at each time point to volume at initiation of treatment) for each drug and control group. $n=7$ mice/group. ${ }^{*} p<0.05 ; * * *<<0.001$.

subcutaneously in green fluorescence protein (GFP)-expressing transgenic nude mice. After two passages in GFP-expressing nude mice, tumors stably containing GFP-expressing stromal cells were harvested and cut into $5 \mathrm{~mm}^{3}$ fragments. After non-transgenic nude mice were anesthetized with a ketamine mixture, an approximately $1-\mathrm{cm}$ skin incision was made at the middle of the abdomen. 8-0 nylon sutures were used to implant tumor fragments onto the cecum Wounds were closed using 6-0 nylon sutures as described before (14). The schematic diagram to establish a CRC PDOX model is shown in Figure 1A.

Treatment study design. Six weeks after orthotopic implantation of CRC-GFP tumors, the abdomen of the PDOX mice was opened to observe tumor growth. The PDOX mice were randomized into 3 groups ( 7 mice/per treatment group) by measuring tumor size: Group
1 (G1), control group (no treatment); Group 2 (G2), OXA+5-FU (OXA $6 \mathrm{mg} / \mathrm{kg}$; 5-FU $50 \mathrm{mg} / \mathrm{kg}$; i.p., weekly for 2 weeks); Group 3 (G3), TRAB+ OXA+5-FU (0.15 mg/kg, i.v.; OXA $6 \mathrm{mg} / \mathrm{kg}$; 5-FU $50 \mathrm{mg} / \mathrm{kg}$; i.p., weekly for 2 weeks) (Figure $1 \mathrm{~B}$ ). Tumor length, width and mouse body weight were measured twice a week. Tumor volume was calculated by the following formula: tumor volume $\left(\mathrm{mm}^{3}\right)=$ length $(\mathrm{mm}) \times$ width $(\mathrm{mm}) \times$ width $(\mathrm{mm}) \times 1 / 2$. Data are presented as mean \pm SD. Mice were imaged with the Fluor Vivo Imaging System (INDEC Biosystem, Santa Clara, CA, USA) (28).

Histological analysis. Fresh tumor samples were fixed in $10 \%$ formalin and embedded in paraffin before sectioning and staining. Four- $\mu \mathrm{m}$ tissue sections were deparaffinized in xylene and rehydrated in an ethanol series. Hematoxylin and eosin (H\&E) staining was carried out according to a standard protocol. 


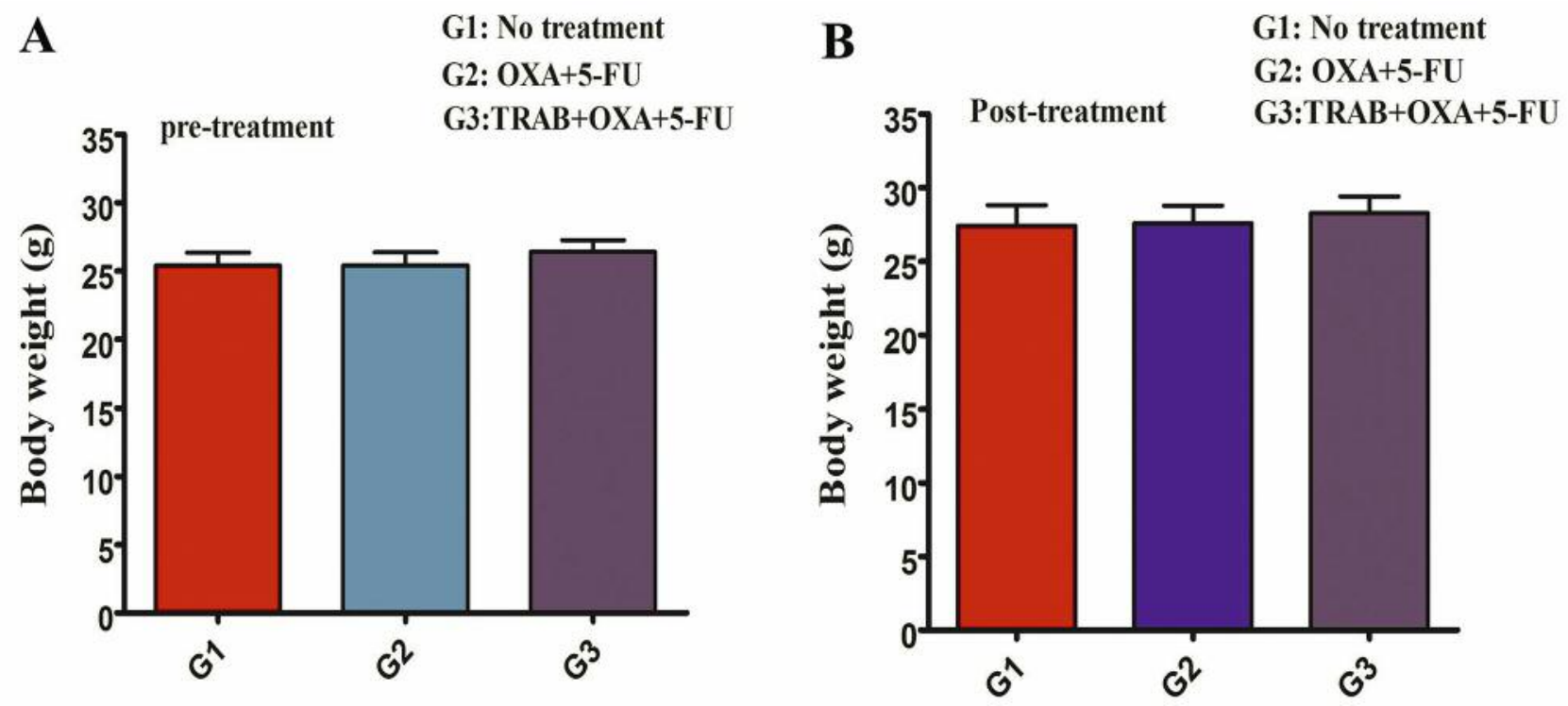

Figure 3. Effect of drugs on mouse body weight. Bar graph shows body weight in each group at pre-treatment (A) and 2 weeks post-treatment (B). There were no significant differences between any group.

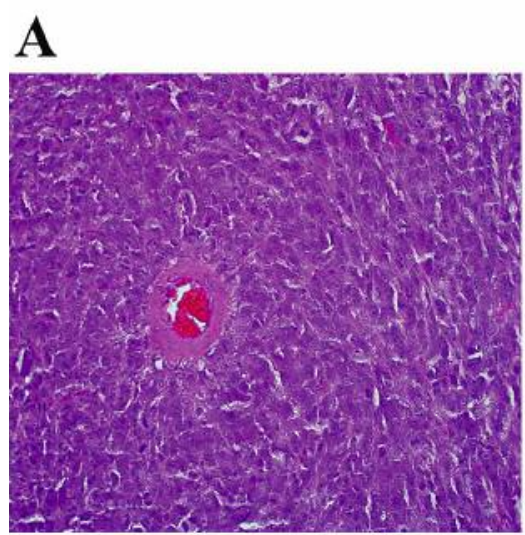

G1: No treatment

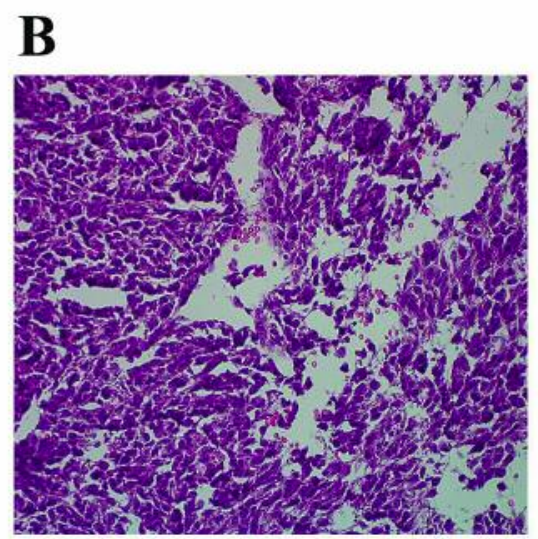

G2: OXA+5-FU

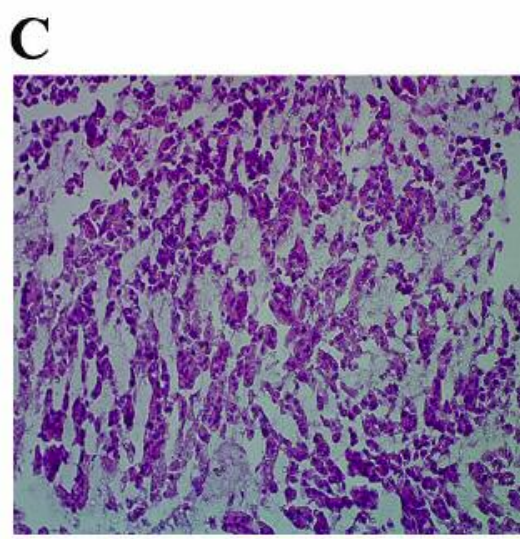

G3: TRAB+OXA+5-FU

Figure 4. Histology of colorectal cancer PDOX mouse model in treated and untreated tumors. Hematoxylin and eosin (H\&E)-stained sections of the (A) Untreated control group. (B) OXA+5-FU treated group, and (C) TRAB+OXA+5-FU treated group. Microscope magnification is 200x.

Histological visualization was performed with a BHS system microscope and images were acquired with INFINITY ANALYZE software (Lumenera Corporation, Ottawa, Canada) (29).

Statistical analysis. All statistical analyses were performed using GraphPad Prism 5 software (GraphPad Software, Inc. La Jolla, CA, USA). Data were analyzed by ANOVA with Tukey's post-hoc test when more than two groups were compared. The data were expressed as the mean $\pm \mathrm{SD}$. A $p$-value of $<0.05$ was considered to be statistically significant.

\section{Results}

Drug efficacy. To test the efficacy of each drug in the CRC PDOX mouse models, six weeks following orthotopic implantation, mice with tumors were randomized into three groups to initiate treatment (Figure 1B). The tumor volumes at the endpoint of the experiment were: G1 untreated control, $514.8 \pm 20.3 \mathrm{~mm}^{3}$ (Figure 2A); G2 OXA+5-FU, 185.4 \pm 24.3 $\mathrm{mm}^{3}$ (Figure 2B); G3 TRAB+OXA+5-FU, $127 \pm 12 \mathrm{~mm}^{3}$ 
(Figure 2C). The control group (G1) tumors grew more than four times larger after 2 weeks compared to the time of the initial treatment (tumor-volume ratio $=4.65 \pm 1.48$ ). In the $\mathrm{OXA}+5-\mathrm{FU}$ group (G2), at the endpoint, there was significant inhibition in tumor growth compared to the control group (tumor-volume ratio $=1.67 \pm 1.77, p<0.001$ ). The TRAB+OXA +5 -FU combination group (G3) arrested tumor growth (tumorvolume ratio $=1.15 \pm 0.88, p<0.001$, compared to the control) (Figure 2D). The TRAB+OXA+5-FU (G3) group resulted in a greater inhibition of tumor growth than the OXA+5-FU group (G2) $(p<0.05)$ (Figure 2D).

Effect of drug treatment on body weight. There was no significant difference observed in body weight in all three groups (Figure 3A, B).

Tumor histology. Histologically, the un-treated control tumor mainly comprised viable cancer cells (Figure 4A). In the tumors treated with $\mathrm{OXA}+5-\mathrm{FU}$, cancer-cell density was lower than that of the control (Figure 4B, C). The strongest efficacy was observed with the combination of TRAB+OXA+5-FU. In this group, cancer cell density was the lowest among all three groups (Figure 4C).

\section{Discussion}

$\mathrm{OXA}+5-\mathrm{FU}$ is first line treatment for $\mathrm{CRC}(30,31)$. Although OXA combined with 5-FU showed a response in the majority of CRC cases, virtually all the responses are incomplete because patients have recurrences. In order to develop an effective curative strategy, the combination of $\mathrm{TRAB}+\mathrm{OXA}+5-\mathrm{FU}$ was tested to see whether it is efficacious in inhibiting the growth of a CRC PDOX mouse model. We found that the combination of TRAB+OXA+5-FU was more effective compared to the $\mathrm{OXA}+5-\mathrm{FU}$ regimen.

TRAB has been previously shown to re-sensitize resistant cells in some tumors (32). TRAB has also been shown to be efficacious in sarcoma (33-36), recurrent ovarian cancer (37), metastatic breast cancer (38), juvenile myelomonocytic leukemia, and chronic myelomonocytic leukemia (39) and we found that TRAB was effective in PDOX models of sarcoma (40-43).

Although, some studies have shown that TRAB may be effective for CRC $(23,25,26)$, no studies have examined the efficacy of the combination of TRAB+OXA+5-FU on CRC. In the present study, we showed that $\mathrm{TRAB}+\mathrm{OXA}+5-\mathrm{FU}$ was highly effective against a PDOX mouse model of CRC, suggesting the use of this combination in the clinic.

\section{Conflicts of Interest}

GWZ, YS and RMH are unpaid affiliates of Anticancer Inc. MZ and $\mathrm{QH}$ are employees of AntiCancer Inc. AntiCancer Inc. uses PDOX models for contract research. The authors declare no conflicts of interest regarding this study.

\section{Authors' Contributions}

GWZ, and J-XY designed the study, modified the figures and wrote draft manuscript; GWZ performed the experiments; MZ, QHH and YS gave help in the experiments; SRS and RMH revised the manuscript. All Authors approved the final manuscript.

\section{Acknowledgements}

This study was supported by the National Natural Science Foundation of China (No.81702424 and 81872364), The Joint Funds for the Innovation of Science and Technology, Fujian Province(No.2017Y9092), The Fujian Provincial Health Department Young and Middle-aged Talents Training Project(No.2018-ZQN46), The Project of Science and Technology Research Program in Fujian Province (No. 2016B044), The Fujian Provincial Natural Science Foundation (No.2018J05127), the National Clinical Key Specialty Construction Project (General Surgery) of China. This paper is dedicated to the memory of A.R. Moossa, MD, Sun Lee, MD, Professor Li Jiaxi, and Masaki Kitajima, MD.

\section{References}

1 Yang AD, Fan F, Camp ER, van Buren G, Liu W, Somcio R, Gray MJ, Cheng H, Hoff PM and Ellis LM: Chronic oxaliplatin resistance induces epithelial-to-mesenchymal transition in colorectal cancer cell lines. Clin Can Res 12(14 Pt 1): 4147-4153, 2006. PMID: 16857785. DOI: 10.1158/1078-0432.CCR-06-0038

2 Alberts SR, Horvath WL, Sternfeld WC, Goldberg RM, Mahoney MR, Dakhil SR, Levitt R, Rowland K, Nair S, Sargent DJ and Donohue JH: Oxaliplatin, fluorouracil, and leucovorin for patients with unresectable liver-only metastases from colorectal cancer: a North Central Cancer Treatment Group phase II study. J Clin Oncol 23(36): 9243-9249, 2005. PMID: 16230673. DOI: 10.1200/JCO.2005.07.740

3 Goldberg RM, Sargent DJ, Morton RF, Fuchs CS, Ramanathan RK, Williamson SK, Findlay BP, Pitot HC and Alberts SR: A randomized controlled trial of fluorouracil plus leucovorin, irinotecan, and oxaliplatin combinations in patients with previously untreated metastatic colorectal cancer. J Clin Oncol 22(1): 23-30, 2004. PMID: 14665611. DOI: 10.1200/JCO.2004.09.046

4 Hoffman RM: Patient-derived orthotopic xenografts: better mimic of metastasis than subcutaneous xenografts. Nat Rev Cancer 15(8): 451-452, 2015. PMID: 26422835. DOI: 10.1038/nrc3972

5 Hiroshima Y, Maawy AA, Katz MH, Fleming JB, Bouvet M, Endo I and Hoffman RM: Selective efficacy of zoledronic acid on metastasis in a patient-derived orthotopic xenograft (PDOX) nudemouse model of human pancreatic cancer. J Surg Oncol 111(3): 311-315, 2015. PMID: 25394368. DOI: 10.1002/jso.23816

6 Hiroshima Y, Zhang Y, Zhang N, Maawy A, Mii S, Yamamoto M, Uehara F, Miwa S, Yano S, Murakami T, Momiyama M, Chishima T, Tanaka K, Ichikawa Y, Bouvet M, Murata T, Endo I and Hoffman RM: Establishment of a patient-derived orthotopic xenograft (PDOX) model of HER-2-positive cervical cancer expressing the clinical metastatic pattern. PloS One 10(2): e0117417, 2015. PMID: 25689852. DOI: 10.1371/journal.pone.0117417

7 Hiroshima Y, Zhang Y, Zhang N, Uehara F, Maawy A, Murakami T, Mii S, Yamamoto M, Miwa S, Yano S, Momiyama M, Mori R, Matsuyama R, Chishima T, Tanaka K, Ichikawa Y, Bouvet M, Endo I and Hoffman RM: Patient-derived orthotopic xenograft 
(PDOX) nude mouse model of soft-tissue sarcoma more closely mimics the patient behavior in contrast to the subcutaneous ectopic model. Anticancer Res 35(2): 697-701, 2015. PMID: 25667448.

8 Hiroshima Y, Zhao M, Maawy A, Zhang Y, Katz MH, Fleming JB, Uehara F, Miwa S, Yano S, Momiyama M, Suetsugu A, Chishima T, Tanaka K, Bouvet M, Endo I and Hoffman RM: Efficacy of Salmonella typhimurium A1-R versus chemotherapy on a pancreatic cancer patient-derived orthotopic xenograft (PDOX). J Cell Biochem 115(7): 1254-1261, 2014. PMID: 24435915. DOI: $10.1002 /$ jcb. 24769

9 Hoffman RM: Patient-derived orthotopic xenograft (PDOX) models of melanoma. Int J Mol Sci 18(9): E1875, 2017. PMID: 28858204. DOI: $10.3390 / \mathrm{ijms} 18091875$

10 Murakami T, Murata T, Kawaguchi K, Kiyuna T, Igarashi K, Hwang HK, Hiroshima Y, Hozumi C, Komatsu S, Kikuchi T, Lwin TM, Delong JC, Miyake K, Zhang Y, Tanaka K, Bouvet M, Endo I and Hoffman RM: Cervical cancer patient-derived orthotopic xenograft (PDOX) is sensitive to cisplatinum and resistant to nab-paclitaxel. Cell Cycle 237(1): 61-65, 2017. PMID: 28011474. DOI: 10.21873/anticanres.11289

11 Kawaguchi K, Igarashi K, Murakami T, Kiyuna T, Nelson SD, Dry SM, Li Y, Russell TA, Singh AS, Chmielowski B, Unno M, Eilber FC and Hoffman RM: Combination of gemcitabine and docetaxel regresses both gastric leiomyosarcoma proliferation and invasion in an imageable patient-derived orthotopic xenograft (iPDOX) model. Cell Cycle 16(11): 1063-1069, 2017. PMID: 28426279. DOI: $10.1080 / 15384101.2017 .1314406$

12 Murakami T, Singh AS, Kiyuna T, Dry SM, Li Y, James AW, Igarashi K, Kawaguchi K, DeLong JC, Zhang Y, Hiroshima Y, Russell T, Eckardt MA, Yanagawa J, Federman N, Matsuyama R, Chishima T, Tanaka K, Bouvet M, Endo I, Eilber FC and Hoffman RM: Effective molecular targeting of CDK4/6 and IGF-1R in a rare FUS-ERG fusion CDKN2A-deletion doxorubicin-resistant Ewing's sarcoma patient-derived orthotopic xenograft (PDOX) nude-mouse model. Oncotarget 7(30): 47556-47564, 2016. PMID: 27286459. DOI: 10.18632 oncotarget.9879

13 Hiroshima Y, Maawy A, Metildi CA, Zhang Y, Uehara F, Miwa S, Yano S, Sato S, Murakami T, Momiyama M, Chishima T, Tanaka K, Bouvet M, Endo I and Hoffman RM: Successful fluorescence-guided surgery on human colon cancer patientderived orthotopic xenograft mouse models using a fluorophoreconjugated anti-CEA antibody and a portable imaging system. J Laparoendosc Adv Surg Tech A 24(4): 241-247, 2014. PMID: 24494971. DOI: 10.1089/lap.2013.0418

$14 \mathrm{Fu}$ XY, Besterman JM, Monosov A and Hoffman RM: Models of human metastatic colon cancer in nude mice orthotopically constructed by using histologically intact patient specimens. Proc Natl Acad Sci USA 88: 9345-9349, 1991. PMID: 1924398. DOI: $10.1073 /$ pnas.88.20.9345

15 Bhattacharya A, Turowski SG, San Martin ID, Rajput A, Rustum YM, Hoffman RM and Seshadri M: Magnetic resonance and fluorescence-protein imaging of the anti-angiogenic and antitumor efficacy of selenium in an orthotopic model of human colon cancer. Anticancer Res 31(2): 387-393, 2011. PMID: 21378316 .

16 Ishihara Y, Matsunaga K, Iijima H, Hasegawa G, Suzuki T, Sato A, Kobayashi T, Yang M and Hoffman RM: The combination of 5-FU, leucovorin and CPT-11 (FOLFIRI) prolongs survival through inhibition of metastasis in an orthotopic model of colon cancer. Anticancer Res 30(2): 403-408, 2010. PMID: 20332446.
17 Ji Y, Hayashi K, Amoh Y, Tsuji K, Yamauchi K, Yamamoto N, Tsuchiya H, Tomita K, Bouvet $\mathrm{M}$ and Hoffman RM: The camptothecin derivative CPT-11 inhibits angiogenesis in a dualcolor imageable orthotopic metastatic nude mouse model of human colon cancer. Anticancer Res 27(2): 713-718, 2007. PMID: 17465193.

18 Ma H, Das T, Pereira S, Yang Z, Zhao M, Mukerji P and Hoffman RM: Efficacy of dietary antioxidants combined with a chemotherapeutic agent on human colon cancer progression in a fluorescent orthotopic mouse model. Anticancer Res 29(7): 24212426, 2009. PMID: 19596909.

19 Park JH, Zhao M, Oshiro H, Miyake K, Higuchi T, Reynoso J, Razmjooei S, Bouvet M, Clary B, Zhang Z, Sugisawa N, Yamamoto J, Singh SR and Hoffman RM: Peritoneal metastases in a patient-derived orthotopic xenograft (PDOX) model of colon cancer imaged non-invasively via red fluorescent protein labeled stromal cells. Anticancer Res 39(7): 3463-3467, 2019. PMID: 31262870. DOI: 10.21873/anticanres.13492

20 Yoon SN, Park JH, Lwin TM, Miyake K, Singh SR, Hoffman RM and Bouvet M: Tumor-sealing surgical orthotopic implantation of human colon cancer in nude mice induces clinically-relevant metastases without early peritoneal carcinomatosis. Anticancer Res 39(8): 4065-4071, 2019. PMID: 31366489. DOI: 10.21873/ anticanres. 13563

21 Park JH, Zhao M, Han Q, Sun Y, Higuchi T, Sugisawa N, Yamamoto J, Singh SR, Clary B, Bouvet M and Hoffman RM: Efficacy of oral recombinant methioninase combined with oxaliplatinum and 5-fluorouracil on primary colon cancer in a patient-derived orthotopic xenograft mouse model. Biochem Biophys Res Commun 518(2): 306-310, 2019. PMID: 31421825. DOI: $10.1016 /$ j.bbrc.2019.08.051

22 H Hendriks HR, Fiebig HH, Giavazzi R, Langdon SP, Jimeno JM and Faircloth GT: High antitumour activity of ET743 against human tumour xenografts from melanoma, non-small-cell lung and ovarian cancer. Ann Oncol 10(10): 1233-1240, 1999. PMID: 10586342. DOI: 10.1023/a:1008364727071

23 Izbicka E, Lawrence R, Raymond E, Eckhardt G, Faircloth G, Jimeno J, Clark G and Von Hoff DD: In vitro antitumor activity of the novel marine agent, ecteinascidin-743 (ET-743, NSC648766) against human tumors explanted from patients. Ann Oncol 9(9): 981-987, 1998. PMID: 9818072. DOI: 10.1023/ A: 1008224322396

24 Carter NJ and Keam SJ: Trabectedin: a review of its use in the management of soft tissue sarcoma and ovarian cancer. Drugs 67(15): 2257-2276, 2007. PMID: 17927287. DOI: 10.2165/ 00003495-200767150-00009

25 Stevens EV, Nishizuka S, Antony S, Reimers M, Varma S, Young L, Munson PJ, Weinstein JN, Kohn EC and Pommier Y: Predicting cisplatin and trabectedin drug sensitivity in ovarian and colon cancers. Mol Cancer Ther 7(1): 10-18, 2008. PMID: 18187810. DOI: 10.1158/1535-7163.MCT-07-0192

26 Twelves C, Hoekman K, Bowman A, Vermorken JB, Anthoney A, Smyth J, van Kesteren C, Beijnen JH, Uiters J, Wanders J, Gomez J, Guzmán C, Jimeno J and Hanauske A: Phase I and pharmacokinetic study of Yondelis (Ecteinascidin-743; ET-743) administered as an infusion over $1 \mathrm{~h}$ or $3 \mathrm{~h}$ every 21 days in patients with solid tumours. Eur J Cancer 39(13): 1842-1851, 2003. PMID: 12932661. DOI: 10.1016/s0959-8049(03)00458-1

27 Igarashi K, Kawaguchi K, Kiyuna T, Miyake K, Miyake M, Li Y, Nelson SD, Dry SM, Singh AS, Elliott IA, Russell TA, Eckardt 
MA, Yamamoto N, Hayashi K, Kimura H, Miwa S, Tsuchiya H, Eilber FC and Hoffman RM: Temozolomide regresses a doxorubicin-resistant undifferentiated spindle-cell sarcoma patient-derived orthotopic xenograft (PDOX): precision-oncology nude-mouse model matching the patient with effective therapy. J Cell Biochem 119(8): 6598-6603, 2018. PMID: 29737543. DOI: $10.1002 /$ jcb. 26792

28 Oshiro H, Kiyuna T, Tome Y, Miyake K, Kawaguchi K, Higuchi T, Miyake M, Zhang Z, Razmjooei S, Barangi M, Wangsiricharoen S, Nelson SD, Li Y, Bouvet M, Singh SR, Kanaya F and Hoffman RM: Detection of metastasis in a patient-derived orthotopic xenograft (PDOX) model of undifferentiated pleomorphic sarcoma with red fluorescent protein. Anticancer Res 39(1): 81-85, 2019. PMID: 30591443. DOI: 10.21873/anticanres.13082

29 Igarashi K, Kawaguchi K, Murakami T, Kiyuna T, Miyake K, Singh AS, Nelson SD, Dry SM, Li Y, Yamamoto N, Hayashi K, Kimura H, Miwa S, Tsuchiya H, Eilber FC and Hoffman RM: High efficacy of pazopanib on an undifferentiated spindle-cell sarcoma resistant to first-line therapy is identified with a patientderived orthotopic xenograft (PDOX) nude mouse model. J Cell Biochem 118(9): 2739-2743, 2017. PMID: 28176365. DOI: $10.1002 /$ jcb. 25923

30 Nautiyal J, Kanwar SS, Yu Y and Majumdar AP: Combination of dasatinib and curcumin eliminates chemo-resistant colon cancer cells. J Mol Signal 6: 7, 2011. PMID: 217744804. DOI: 10.1186/ 1750-2187-6-7

31 Li P, Zhang X, Wang H, Wang L, Liu T, Du L, Yang Y and Wang C: MALAT1 is associated with poor response to oxaliplatin-based chemotherapy in colorectal cancer patients and promotes chemoresistance through EZH2. Mol Cancer Ther 16(4): 739-751, 2017. PMID: 28069878. DOI: 10.1158/15357163.MCT-16-0591

32 Loria R, Laquintana V, Bon G, Trisciuoglio D, Frapolli R, Covello R, Amoreo CA, Ferraresi V, Zoccali C, Novello M, Del Bufalo D, Milella M, Biagini R, D'Incalci M and Falcioni R: HMGA1/E2F1 axis and NFkB pathways regulate LPS progression and trabectedin resistance. Oncogene 37(45): 5926-5938, 2018. PMID: 29980789. DOI: $10.1038 / \mathrm{s} 41388-018-0394-\mathrm{x}$

33 Gronchi A, Bui BN, Bonvalot S, Pilotti S, Ferrari S, Hohenberger P, Hohl RJ, Demetri GD, Le Cesne A, Lardelli P, Pérez I, Nieto A, Tercero JC, Alfaro V, Tamborini E and Blay JY: Phase II clinical trial of neoadjuvant trabectedin in patients with advanced localized myxoid liposarcoma. Ann Oncol 23(3): 771-776, 2012. PMID: 21642514. DOI: 10.1093/annonc/mdr265

34 De Sanctis R, Marrari A, Marchetti S, Mussi C, Balzarini L, Lutman FR, Daolio P, Bastoni S, Bertuzzi AF, Quagliuolo V and Santoro A: Efficacy of trabectedin in advanced soft tissue sarcoma: beyond lipo- and leiomyosarcoma. Drug Des Devel Ther 9: 5785-5791, 2015. PMID: 26604682. DOI: 10.2147/DDDT. S92395

35 Bui-Nguyen B, Butrynski JE, Penel N, Blay JY, Isambert N, Milhem M, Kerst JM, Reyners AK, Litière S, Marréaud S, Collin $\mathrm{F}$ and van der Graaf WT: European organisation for research and treatment of cancer soft tissue and bone sarcoma group (EORTC/STBSG) and the sarcoma alliance for research through collaboration (SARC): a phase IIb multicentre study comparing the efficacy of trabectedin to doxorubicin in patients with advanced or metastatic untreated soft tissue sarcoma: the TRUSTS trial. Eur J Cancer 51(10): 1312-1320, 2015. PMID: 25912752. DOI: $10.1016 /$ j.ejca.2015.03.023
36 Takahashi M, Takahashi S, Araki N, Sugiura H, Ueda T, Yonemoto T, Morioka H, Hiraga H, Hiruma T, Kunisada T, Matsumine A, Shimura M and Kawai A: Efficacy of trabectedin in patients with advanced translocation-related sarcomas: pooled analysis of two phase II studies. Oncologist 22(8): 979-988, 2017. PMID: 28526720. DOI: 10.1634/theoncologist.2016-0064

37 Adam JP, Boumedien F, Letarte N and Provencher D: Single agent trabectedin in heavily pretreated patients with recurrent ovarian cancer. Gynecol Oncol 147(1): 47-53, 2017. PMID: 28751117. DOI: 10.1016/j.ygyno.2017.07.123

38 Ghouadni A, Delaloge S, Lardelli P, Kahatt C, Byrski T, Blum JL, Gonçalves A, Campone M, Nieto A, Alfaro V, Cullell-Young M and Lubinski J: Higher antitumor activity of trabectedin in germline BRCA2 carriers with advanced breast cancer as compared to BRCA1 carriers: A subset analysis of a dedicated phase II trial. Breast 34: 18-23, 2017. PMID: 28467918. DOI: 10.1016/j.breast.2017.04.006

39 Romano M, Della Porta MG, Gallì A, Panini N, Licandro SA, Bello E, Craparotta I, Rosti V, Bonetti E, Tancredi R, Rossi M, Mannarino L, Marchini S, Porcu L, Galmarini CM, Zambelli A, Zecca M, Locatelli F, Cazzola M, Biondi A, Rambaldi A, Allavena $\mathrm{P}$, Erba $\mathrm{E}$ and D'Incalci M: Antitumour activity of trabectedin in myelodysplastic/myeloproliferative neoplasms. $\mathrm{Br} \mathrm{J}$ Cancer 116(3): 335-343, 2017. PMID: 28072764. DOI: 10.1038/bjc. 2016.424

40 Higuchi T, Miyake K, Oshiro H, Sugisawa N, Yamamoto N, Hayashi K, Kimura H, Miwa S, Igarashi K, Chawla SP, Bouvet M, Singh SR, Tsuchiya H and Hoffman RM: Trabectedin and irinotecan combination regresses a cisplatinum-resistant osteosarcoma in a patient-derived orthotopic xenograft nudemouse model. Biochem Biophys Res Commun 513: 326-331, 2019. PMID: 30955860. DOI: 10.1016/j.bbrc.2019.03.191

41 Zhang Z, Hu K, Kiyuna T, Miyake K, Kawaguchi K, Igarashi K, Nelson SD, Li Y, Singh SR and Hoffman RM: A patient-derived orthotopic xenograft (PDOX) nude-mouse model precisely identifies effective and ineffective therapies for recurrent leiomyosarcoma. Pharmacol Res 142: 169-175, 2019. PMID: 30807865. DOI: 10.1016/j.phrs.2019.02.021

42 Kiyuna T, Tome Y, Murakami T, Kawaguchi K, Igarashi K, Miyake K, Miyake M, Li Y, Nelson SD, Dry SM, Singh AS, Russell TA, Elliott I, Singh SR, Kanaya F, Eilber FC and Hoffman RM: Trabectedin arrests a doxorubicinresistant PDGFRAactivated liposarcoma patient-derived orthotopic xenograft (PDOX) nude mouse model. BMC Cancer 18(1): 840, 2018. PMID: 30126369. DOI: 10.1186/s12885-018-4703-0

43 Igarashi K, Murakami T, Kawaguchi K, Kiyuna T, Miyake K, Zhang Y, Nelson SD, Dry SM, Li Y, Yanagawa J, Russell TA, Singh AS, Tsuchiya H, Elliott I, Eilber FC and Hoffman RM: A patient-derived orthotopic xenograft (PDOX) mouse model of a cisplatinum-resistant osteosarcoma lung metastasis that was sensitive to temozolomide and trabectedin: implications for precision oncology. Oncotarget 8: 62111-62119, 2017. PMID: 28977930. DOI: 10.18632/oncotarget.19095

Received October 10, 2019

Revised October 21, 2019

Accepted October 22, 2019 